\title{
A Practical Example on Uncertainty Evaluation: Spectrophotometric Determination of $\mathrm{pK}_{\mathrm{a}}$
}

\author{
E. J. Díaz-Montaña, A. Alcázar, J. M. Jurado*, F. Pablos \\ J. Marcos Jurado, Department of Analytical Chemistry, University of Seville, c/ Profesor García González 1, \\ Seville, Spain.
}

*Corresponding Author: J. M. Jurado, Department of Analytical Chemistry, University of Seville, c/ Profesor García González 1, Seville, Spain.

\begin{abstract}
A practical example, focused on the evaluation of uncertainty and its propagation in spectrophotometric determination of ionization constants, is proposed in this work. The Hildebrand - Reilley method has been used in order to calculate the acetaminofen $p K_{a}$ value. After applying this method a linear relationship between $\mathrm{pH}$ and a logarithmic term depending on absorbances, was established. The value of $p K_{a}$ is obtained as the intercept of this straight-line and its error is evaluated from least squares calculations. As errors in both variables have to be considered, weighted least squares (WLS) must be used. The evaluation of uncertainty in $\mathrm{pH}$ measurements was carried out according to IUPAC recommendations in the case of glass electrode with two calibration standards. The uncertainty contributions of absorbance and work standard concentration, evaluated according to GUM, have been propagated to Hildebrand - Reilley expression in order to obtain the errors to be used in WLS calculations. Due to the different topics included in this tutorial, it can be considered as a useful tool for training people learning about the evaluation of uncertainty in measurements and its propagation.
\end{abstract}

Keywords: Uncertainty evaluation, weighted least squares, spectrophotometric determination of $p K_{a}$.

\section{INTRODUCTION}

As it can be read in EURACHEM/CITAC Guide for quantifying uncertainty in analytical measurements [1], many important decisions are based on the results of chemical quantitative analysis and, for this reason, is very important to ensure the quality of analytical methods. Nowadays, there has been a great emphasis on the precision of results obtained using a specified analytical method and in establishing their traceability to a defined standard. For this aim, internal quality control procedures, proficiency testing an accreditation have become very useful tools. Chemists are being asked to demonstrate the quality of their results, including their agreement with others results, being measurement uncertainty one useful measure of this. As a consequence of these requirements, our students are expected to be able to apply measurement uncertainty evaluation and propagation. In this work, we propose a training practical example that can be used by people learning about the evaluation of uncertainty in measurements and its propagation in different cases. The chosen example is the photometric determination of the ionization constant of acetaminophen by measuring the absorbance of an acetaminophen solution at different $\mathrm{pH}$ values. According to Hildebrand and Reilley method [2], the next relation can be established:

$p H=p K_{a}+\log \frac{A_{I}}{A_{I I} A_{I}}$

where $\mathrm{A}_{\mathrm{I}}$ is the difference between the absorbance at acid $\mathrm{pH}$ and absorbance at a given $\mathrm{pH}$ and $\mathrm{A}_{\mathrm{II}}$ the difference between the absorbance at acid and basic $\mathrm{pH}$ respectively.

When plotting $\mathrm{pH}$ vs. the logarithmic term, a linear straight is obtained. The value of $\mathrm{pK}_{\mathrm{a}}$ is calculated as the intercept of this straight-line and its error is obtained from least squares calculations. In this case we must take into account the uncertainties in $\mathrm{pH}$ values as well as in the logarithmic term of absorbances and, for this reason, weighted least squares must be used. 
The selected example includes different topics about uncertainty evaluation as well as the use of weighted linear regression. It can be considered as a good academic exercise for students in the last courses. In this way, some theoretical considerations must be consolidated.

\subsection{GUM Uncertainty Evaluation}

To carry out the measurement of uncertainty evaluation, according to the Guide to the expression of Uncertainty in Measurement (gum) [1, 3], different steps must be considered. In the first one, specification step, an algebraic relationship is established between the measurand $\mathrm{Z}$ and the individual factors $\mathrm{Xi}$ that affect the measuring process:

$$
Z=F\left(X_{1}, \ldots X_{i}, \ldots X_{n}\right)
$$

Once the model equation is specified the sources of significant uncertainty for the $X_{i}$ parameters must be identified and their standard uncertainties quantified. In the combination step the measurand standard uncertainty $\mathrm{u}(Z)$ is evaluated from the standard uncertainties of the factors $X_{\mathrm{i}}$ and covariances $\operatorname{cov}\left(\mathrm{X}_{\mathrm{i}}, \mathrm{X}_{\mathrm{j}}\right)$ between correlated parameters, by applying the law [4] of propagation of errors (LPE).

$$
u^{2}(Z)=\sum_{i=1}^{n}\left(\frac{\partial Z}{\partial X_{i}}\right)^{2} u^{2}\left(X_{i}\right)+2 \sum_{i=1}^{n} \sum_{j=1}^{n}\left(\frac{\partial Z}{\partial X_{i}} \frac{\partial Z}{\partial X_{j}}\right) \operatorname{cov}\left(X_{i}, X_{j}\right)
$$

Finally, the expanded uncertainty $\mathrm{U}(\mathrm{Z})$ is calculated by multiplying the standard uncertainty by a coverage factor [1] $\mathrm{k}$. If $\mathrm{Z}$ is assumed to be normally distributed, at $95 \%$ confidence level, $\mathrm{k}=2$.

\subsection{Linear regression}

Analysts are very familiar with the application of linear regression techniques when they are finding out the relationship between sample (X) and signal (Y) domains in quantitative analysis [5]. It is very common the use of ordinary least squares (OLS) regression, based on the model equation $Y=b X+a$ $+\varepsilon$, to establish this relationship between the variables, $\mathrm{X}$ and $\mathrm{Y}$. This equation correspond to a straight line with slope $b$ and intercept $a$, being $\varepsilon$ the random deviation of the model [6]. Some assumptions have to be considered to perform OLS regression. This model do not take into account errors in the independent variable $x$, they are only in the dependent variable $y$ by means of the pure error variance of the replicated response $\left(s_{y_{i}}^{2}\right)$ at each level $x$. In addition, this variance has to be constant in the several levels (homocedasticity) and the values of y must be normally distributed [5, 7]. In these conditions, the regression parameters are estimated from the $\mathrm{n}$ pairs $\left(\mathrm{x}_{\mathrm{i}}, \mathrm{y}_{\mathrm{i}}\right)$ of experimental data by minimizing the sum of squares of residuals

$$
S=\sum_{i=1}^{n}\left(y_{i}-a-b x_{i}\right)^{2}
$$

In case that measuring errors were different at each level $x$ (heterocedasticity), weighted least squares (WLS) must be applied and the sum to minimize turns into

$$
S=\sum_{i=1}^{n} w_{i}\left(y_{i}-a_{w}-b_{w} x_{i}\right)^{2}
$$

being $a_{w}$ and $b_{w}$ the intercept and the slope obtained by WLS and $w_{i}$ the weights obtained as

$$
w_{i}=1 / s_{y_{i}}^{2}
$$

But there are situations in which errors in both axes must be taken into account, for example, when propagating the uncertainty of the standards of calibration to the final result, performing method comparison [8-10] or using two measured variables to obtain any chemical constant [11]. In these cases, WLS must be used with weights

$$
w_{i}=\frac{1}{s_{y_{i}}^{2}+b_{w}^{2} s_{x_{i}}^{2}-2 b_{w} \operatorname{cov}\left(x_{i}, y_{i}\right)}
$$


where $s_{x_{i}}^{2}$ and $s_{y_{i}}^{2}$ are the variances of $\mathrm{x}_{\mathrm{i}}$ and $\mathrm{y}_{\mathrm{i}}$, respectively and $\operatorname{cov}\left(x_{i}, y_{i}\right)$ is the covariance between $\mathrm{x}_{\mathrm{i}}$ and $\mathrm{y}_{\mathrm{i}}$ (normally assumed to be zero). The regression parameters are calculated as

$b_{w}=\frac{\sum_{i=1}^{n} w_{i}\left(x_{i}-x_{w}\right)\left(y_{i}-y_{w}\right)}{\sum_{i=1}^{n} w_{i}\left(x_{i}-x_{w}\right)^{2}}$

$a_{w}=\bar{y}_{w}-b_{w} \bar{x}_{w}$

being

$\bar{x}_{w}=\sum_{i=1}^{n} w_{i} x_{i} / \sum_{i=1}^{n} w_{i}$

and

$$
\bar{y}_{w}=\sum_{i=1}^{n} w_{i} y_{i} / \sum_{i=1}^{n} w_{i}
$$

the weighted means of $x_{i}$ and $y_{i}$ values, respectively.

Taking into account that values of $b_{w}$ and aw depend on the weighting factors and, at the same time, weighting factors depend on $b_{w}$ and $a_{w}$, the use of an iterative algorithm is required.

\section{EXPERIMENTAL}

All chemicals were of ultrapure grade, and ultrapure water $(18.2 \mathrm{M} \Omega \cdot \mathrm{cm})$, obtained from a Milli-Q water purification system (Millipore, Bedford, MA), was used throughout. A $0.0025 \mathrm{M}$ standard solution of acetaminophen (Sigma-Aldrich, Steinhein, Germany) was prepared in a $100 \mathrm{~mL}$ volumetric flask (Type A). Work solutions of $5 \times 10-5 \mathrm{M}$ was prepared in $50 \mathrm{~mL}$ volumetric flasks (Type A) at several $\mathrm{pH}$ values using buffer solutions $0.1 \mathrm{M}$ in both sodium di-hydrogen phosphate and boric acid (Merck, Darmstadt, Germany). The $\mathrm{pH}$ value was adjusted with sodium hydroxyde (Merck) and the ionic strength was fixed to 0.75 with sodium chloride (Panreac, Barcelona, Spain). The $\mathrm{pH}$ measurements were performed using a Crison Basic $20 \mathrm{pH}$-meter equipped with an automatic temperature compensator. The $\mathrm{pH}$-meter was calibrated by a two-point calibration method by using commercial buffers (Crison, Barcelona, Spain) of $\mathrm{pH} 7.00$ and 9.21. The absorbance of these work solutions was measured by triplicate at $258 \mathrm{~nm}$ with a Thermo Spectronic Unicam UV 500 spectrometer. Blank solutions were measured at each $\mathrm{pH}$ value. The obtained absorbance-pH curve is depicted in Fig. 1.

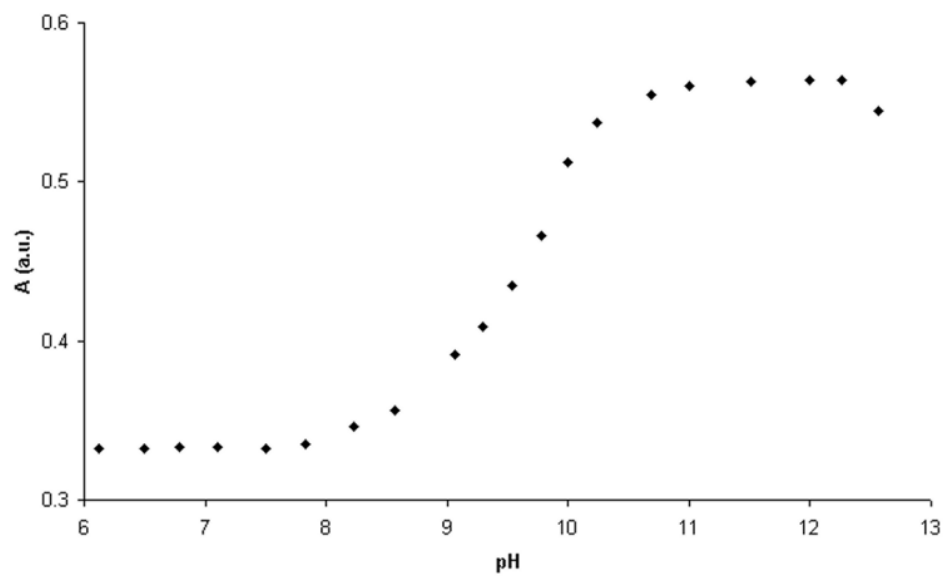

Fig 1. Absorbance-pH curve obtained with $2.5 \times 10^{-5} \mathrm{M}$ solutions of acetaminophen.

\section{RESULTS AND DISCUSSION}

\subsection{Uncertainty in Standard Concentration}

The first step to solve our problem is to evaluate the uncertainty of a $0.1 \mathrm{M}$ acetaminophen standard. The model equation used to obtain the concentration of the standard solution is 


$$
C=\frac{1000 P m}{M V}
$$

where $\mathrm{C}$ is the concentration of the standard $\left(\mathrm{mol} \mathrm{L}^{-1}\right), \mathrm{m}$ the mass of acetaminophen dissolved $(\mathrm{g}), \mathrm{P}$ is the purity, $\mathrm{M}$ is the molecular weight of paracetamol $\left(151.17 \mathrm{~g} \mathrm{~mol}^{-1}\right)$ and $\mathrm{V}$ the volume of the final solution $(100 \mathrm{~mL})$ and the scale factor 1000 is used to convert $\mathrm{mL}$ in L. Error in molecular weight was not considered. The combined standard uncertainty of $\mathrm{C}$ can be calculated, by applying the law of error propagation to Eqn. 12, as:

$$
u(C)=\sqrt{\left(\frac{1000 P}{M V}\right)^{2} u^{2}(m)+\left(\frac{1000 m}{M V}\right)^{2} u^{2}(P)+\left(\frac{1000 m P}{M V^{2}}\right)^{2} u^{2}(V)}
$$

The evaluation and propagation of the uncertainties of mass $(\mathrm{u}(\mathrm{m}))$, purity $(\mathrm{u}(\mathrm{P}))$ and volume $(\mathrm{u}(\mathrm{V}))$ to obtain the uncertainty of calibration standards is full described in literature [1, 12- 13]. The uncertainty associated with the mass of acetaminophen was estimated as $0.05 \mathrm{mg}$, according to the calibration certificate. This is a type B uncertainty and it is assumed a normal distribution. The purity of acetaminophen was obtained from the certificate as $0.99 \pm 0.01 \%$. As no additional information about the uncertainty value is given, a rectangular distribution was assumed and the standard uncertainty was obtained as the value of 0.01 divided by $\sqrt{3}$. The volume has three major influences; calibration, repeatability and temperature effects. Considering the calibration effect, the flask manufacturer quoted a volume of $100 \pm 0.1 \mathrm{~mL}$. Because no confidence level or distribution information was given, triangular distribution is assumed and the standard uncertainty is calculated as the value of 0.1 divided by $\sqrt{6}$. The contribution of repeatability is a type A uncertainty and was evaluated experimentally, in a series of 10 fill and weigh experiments, as $0.02 \mathrm{~mL}$. According to the manufacturer, the flask has been calibrated at a temperature of $20^{\circ} \mathrm{C}$, whereas the laboratory temperature varies between the limits of $\pm 4{ }^{\circ} \mathrm{C}$. The type B uncertainty from this effect was calculated from the estimate of the temperature range and the coefficient of the volume expansion $(2.1 \times 10-4$ $\left.{ }^{\circ} \mathrm{C}^{-1}\right)$, leading to a volume variation of $\pm(100 \times 4 \times 2.1 \times 10-4)= \pm 0.084 \mathrm{~mL}$. The standard uncertainty is calculated using the assumption of a rectangular distribution for the temperature variation. The obtained results are shown in Table 1. As can be seen, purity of acetaminophen is the most contributing source to the uncertainty of the concentration of the standard solution. The weighted mass of acetaminophen is the second source of uncertainty.

Table 1. Uncertainty budget for the preparation of a $2.5 \times 10^{-3} \mathrm{M}$ standard of acetaminophen

\begin{tabular}{|c|c|c|c|c|}
\hline Quantity & Estimate & $\begin{array}{c}\text { Standard } \\
\text { Uncertainty }\end{array}$ & $\begin{array}{c}\text { Sensitivity } \\
\text { coefficient }\end{array}$ & $\begin{array}{c}\text { Uncertainty } \\
\text { contribution }\end{array}$ \\
\hline $\mathrm{P}$ & 0.99 & $5.77 \times 10^{-3}$ & $2.53 \times 10^{-3}$ & $1.46 \times 10^{-5}$ \\
\hline $\mathrm{m}$ & $3.82 \times 10^{-2}$ & $5 \times 10^{-5}$ & $6.55 \times 10^{-2}$ & $3.27 \times 10^{-6}$ \\
\hline $\mathrm{V}$ & 100 & $6.65 \times 10^{-2}$ & & $1.02 \times 10^{-6}$ \\
\hline $\mathrm{V}_{\mathrm{cal}}$ & 0 & $4.08 \times 10^{-2}$ & $2.5 \times 10^{-5}$ & $1.21 \times 10^{-6}$ \\
\hline $\mathrm{V}_{\text {temp }}$ & 0 & $4.85 \times 10^{-2}$ & $2.5 \times 10^{-5}$ & $5 \times 10^{-7}$ \\
\hline $\mathrm{V}_{\mathrm{rep}}$ & 100 & $2 \times 10^{-2}$ & $2.5 \times 10^{-5}$ & \\
\hline $\mathrm{C}$ & $2.5 \times 10^{-3}$ & $1.5 \times 10^{-5}$ & & \\
\hline
\end{tabular}

After $\mathrm{u}(\mathrm{C})$ was obtained, the uncertainty of the work standard was evaluated by applying the law of error propagation to the expression:

$$
C_{s}=\frac{C V_{p}}{V_{f}}
$$

where $\mathrm{C}_{\mathrm{s}}$ is the concentration of the work solution, $\mathrm{V}_{\mathrm{p}}$ is the volume of the $0.1 \mathrm{M}$ solution, measured with a pipette, used to prepare the work solution in a final volume $V_{f}$. The obtained results are shown in Table 2. In this case, the main source of uncertainty is the concentration of the standard solution, due to the effect of purity in their standard uncertainty. Other important contributions are due to the repeatability and calibration influences in the pipetted volume of the standard solution. 
A Practical Example on Uncertainty Evaluation: Spectrophotometric Determination of pKa

Table 2. Uncertainty budget for the preparation of a work solution of $5 \times 10^{-5} \mathrm{M}$ of acetaminophen

\begin{tabular}{|c|c|c|c|c|}
\hline Quantity & Estimate & Standard Uncertainty & Sensitivity coefficient & $\begin{array}{c}\text { Uncertainty } \\
\text { contribution }\end{array}$ \\
\hline $\mathrm{C}$ & $2.5 \times 10^{-3}$ & $1.5 \times 10^{-5}$ & $2 \times 10^{-2}$ & $3.01 \times 10^{-7}$ \\
\hline $\mathrm{Vp}$ & 1 & $2.04 \times 10^{-2}$ & & $5 \times 10^{-5}$ \\
\hline Vp,cal & 0 & $4.08 \times 10^{-3}$ & $5 \times 10^{-5}$ & $2.43 \times 10^{-7}$ \\
\hline Vp,temp & 0 & $4.85 \times 10^{-4}$ & $5 \times 10^{-5}$ & $2 \times 10^{-7}$ \\
\hline Vp,rep & 1 & $4 \times 10^{-3}$ & & $2.45 \times 10^{-8}$ \\
\hline Vf & 50 & $3.98 \times 10^{-2}$ & $1 \times 10^{-6}$ & $2.43 \times 10^{-8}$ \\
\hline Vf,cal & 0 & $2.45 \times 10^{-2}$ & $1 \times 10^{-6}$ & $3 \times 10^{-8}$ \\
\hline Vf,temp & 0 & $2.42 \times 10^{-2}$ & $1 \times 10^{-6}$ & \\
\hline Vf,rep & 50 & $3 \times 10^{-2}$ & & \\
\hline Cs & $5 \times 10^{-5}$ & $4.18 \times 10^{-6}$ & & \\
\hline
\end{tabular}

\subsection{Uncertainty in pH Measurements}

According to IUPAC recommendations [14], the model equation for $\mathrm{pH}$ measurement using a glass electrode with two-standard $\left(\mathrm{S}_{1}\right.$ and $\left.\mathrm{S}_{2}\right)$ calibration is

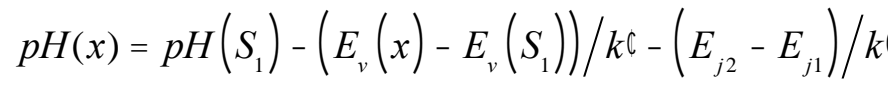

where $\mathrm{Ph}(\mathrm{S} 1)$ is $\mathrm{Ph}$ of standard $1, \mathrm{E}_{\mathrm{v}}\left(\mathrm{S}_{1}\right)$ is the measured potential for standard $1, \mathrm{E}_{\mathrm{v}}(\mathrm{x})$ is the potential at the given $\mathrm{pH}(\mathrm{x}),\left(\mathrm{E}_{\mathrm{j} 2}-\mathrm{E}_{\mathrm{j} 1}\right)$ is the residual liquid junction potential and $\mathrm{k}$ ' is a constant coming from Nernts equation

$\mathrm{k}^{\prime}=\mathrm{RT} \ln 10 / \mathrm{nF}$

This constant can be experimentally obtained, using the potential measurements of two $\mathrm{pH}$ standards, as:

$$
k^{\prime}=\left(E_{v}\left(S_{2}\right) \quad E_{v}\left(S_{1}\right)\right) /\left(p H\left(S_{2}\right) \quad p H\left(S_{1}\right)\right)
$$

The uncertainty of the measured $\mathrm{pH}$ was evaluated by applying LPE to expression 15.

$$
\begin{aligned}
u^{2}(p H(x))= & u^{2}\left(p H\left(S_{1}\right)\right)+\frac{1}{\left(k^{\prime}\right)^{2}}\left(u^{2}\left(E_{v}\left(S_{1}\right)\right)+u^{2}\left(E_{v}(x)\right)+u^{2}\left(E_{j 2} E_{j 1}\right)\right)+ \\
& +\frac{\left(E_{v}(x) E_{v}\left(S_{1}\right)+\left(E_{j 2}\right.\right.}{\left.\left.k_{j 1}\right)\right)^{2}} u^{2}\left(k^{\prime}\right)
\end{aligned}
$$

where $\mathrm{u}(\mathrm{pH}(\mathrm{S} 1))$ is obtained from the standard certificate, $\mathrm{u}\left(\mathrm{E}_{\mathrm{v}}\right)$ was estimated from replicates an $\mathrm{u}\left(\mathrm{E}_{\mathrm{j} 2}-\mathrm{E}_{\mathrm{j} 1}\right)$ for a glass electrode was estimated a $0.6 \mathrm{mV}$ according to IUPAC recommendations [14]. The evaluation of $u\left(k^{\prime}\right)$ was carried out taking into account the contribution of factors in Eqn. 17, the effect of temperature according to Eqn. 16 and the residual liquid junction potential (RLJP).

$u^{2}\left(k^{\prime}\right)=u^{2}\left(k_{E / p H}^{\prime}\right)+u^{2}\left(k_{T}^{\prime}\right)+u^{2}\left(k_{R L J P}^{\prime}\right)$

The uncertainty $\mathrm{u}^{2}\left(\mathrm{k}^{\prime} \Delta \mathrm{E} / \Delta \mathrm{pH}\right)$ was evaluated by applying LPE to Eqn. 17:

$$
\begin{aligned}
& u^{2}\left(k_{E / p H}^{\prime}\right)=\frac{1}{\left(p H\left(S_{2}\right) \quad p H\left(S_{1}\right)\right)^{2}} u^{2}\left(E_{v}\left(S_{2}\right)\right)+u^{2}\left(E_{v}\left(S_{1}\right)\right)+ \\
& +\frac{\left(E_{v}\left(S_{2}\right) E_{v}\left(S_{1}\right)\right)^{2}}{\left(p H\left(S_{2}\right) \quad p H\left(S_{1}\right)\right)^{4}}\left(u^{2}\left(p H\left(S_{2}\right)\right)+u^{2}\left(p H\left(S_{1}\right)\right)\right)
\end{aligned}
$$

Errors in $E_{v}\left(S_{1}\right)$ and $E_{v}\left(S_{2}\right)$ were evaluated from replicates and errors in $\mathrm{pH}\left(\mathrm{S}_{1}\right)$ and $\mathrm{pH}\left(\mathrm{S}_{2}\right)$ were obtained from the standards certificates.

The uncertainty due to the effect of temperature was evaluated as:

$u^{2}\left(k_{T}^{\prime}\right)=\left(\frac{R \ln 10}{n F}\right)^{2} u^{2}(T)$ 
being $\mathrm{u}(\mathrm{T})$ the uncertainty of the thermometer used to measure the laboratory temperature.

Finally, the uncertainty due to RLJP was evaluated according to IUPAC [14] as:

$$
u^{2}\left(k_{R L J P}^{\prime}\right)=\frac{u^{2}\left(E_{j 2} \quad E_{j 1}\right)}{\left(p H\left(S_{2}\right) \quad p H\left(S_{1}\right)\right)^{2}}
$$

Table 3. Uncertainty budget for the practical slope $k$ ' in a two point pH calibration

\begin{tabular}{|c|c|c|c|c|}
\hline Quantity & Estimate & Standard Uncertainty & Sensitivity coefficient & $\begin{array}{c}\text { Uncertainty } \\
\text { contribution }\end{array}$ \\
\hline $\mathrm{pH}\left(\mathrm{S}_{1}\right)$ & 7 & $1 \times 10^{-2}$ & $2.55 \times 10^{-2}$ & $2.55 \times 10^{-4}$ \\
\hline $\mathrm{E}_{\mathrm{v}}\left(\mathrm{S}_{1}\right)$ & 0.005 & $1.15 \times 10^{-3}$ & $4.52 \times 10^{-1}$ & $5.22 \times 10^{-4}$ \\
\hline $\mathrm{pH}\left(\mathrm{S}_{2}\right)$ & 9.21 & $1 \times 10^{-2}$ & $2.55 \times 10^{-2}$ & $2.55 \times 10^{-4}$ \\
\hline $\mathrm{E}_{\mathrm{v}}\left(\mathrm{S}_{2}\right)$ & -0.119 & $1.53 \times 10^{-3}$ & $4.52 \times 10^{-1}$ & $6.91 \times 10^{-4}$ \\
\hline $\mathrm{T}$ & 298.15 & 0.1 & $1.98 \times 10^{-4}$ & $1.98 \times 10^{-5}$ \\
\hline$\left(\mathrm{E}_{\mathrm{j} 2}-\mathrm{E}_{\mathrm{j} 1}\right)$ & $6 \times 10^{-4}$ & $6 \times 10^{-4}$ & $4.52 \times 10^{-1}$ & $2.71 \times 10^{-4}$ \\
\hline $\mathrm{k}^{\prime}$ & 0.0564 & $9.77 \times 10^{-4}$ & & \\
\hline
\end{tabular}

The uncertainty budget for the practical slope $\mathrm{k}^{\prime}$ is shown in Table 3. The principal sources of uncertainty are the measured potentials for $\mathrm{pH}$ standards. Using the final result for $\mathrm{k}$, the uncertainty of the experimental $\mathrm{pH}$ can be established. An example for the case of $\mathrm{pH}=9.54$ is shown in Table 4 . In this case, the highest contributions to the final uncertainty are also due to the measured potentials, but also to the experimental slope.

Table 4. Uncertainty budget for an experimental pH=9.54 using a two-point calibration.

\begin{tabular}{|c|c|c|c|c|}
\hline Quantity & Estimate & Standard Uncertainty & Sensitivity coefficient & $\begin{array}{c}\text { Uncertainty } \\
\text { contribution }\end{array}$ \\
\hline $\mathrm{pH}\left(\mathrm{S}_{1}\right)$ & 7 & $1 \times 10^{-2}$ & 1 & $1 \times 10^{-2}$ \\
\hline $\mathrm{E}_{\mathrm{v}}\left(\mathrm{S}_{1}\right)$ & 0.005 & $1.15 \times 10^{-3}$ & 17.73 & $2.05 \times 10^{-2}$ \\
\hline $\mathrm{E}_{\mathrm{v}}(\mathrm{X})$ & -0.138 & $2 \times 10^{-3}$ & 17.73 & $3.54 \times 10^{-2}$ \\
\hline$\left(\mathrm{E}_{\mathrm{j} 2}-\mathrm{E}_{\mathrm{j} 1}\right)$ & $6 \times 10^{-4}$ & $6 \times 10^{-4}$ & 17.73 & $1.06 \times 10^{-2}$ \\
\hline $\mathrm{k}^{\prime}$ & 0.0564 & $9.77 \times 10^{-4}$ & 44.85 & $4.38 \times 10^{-2}$ \\
\hline $\mathrm{pH}(\mathrm{x})$ & 9.54 & $6.1 \times 10^{-2}$ & & \\
\hline
\end{tabular}

\subsection{Uncertainty in absorbance}

The standard uncertainty in absorbance measurements $(\mathrm{u}(\mathrm{A}))$ was estimated by considering the calibration uncertainty of the instrument $(\mathrm{u}(\mathrm{Acal}))$, the repeatability of the measurements $(\mathrm{u}($ Arepeat $)$ ) and the uncertainty due to the sample concentration (u(Aconc)) $[15,16]$. The calibration uncertainty of the spectrometer was obtained from the validation certificate. Performing the measurement of the standard solution three times and calculating the standard deviation of the obtained results evaluated the repeatability. The uncertainty due to sample concentration was evaluated from the expression of Lambert-Beer law:

$A=L C$

being $\varepsilon$ the molar absorption coefficient, $\mathrm{L}$ is the absorption path-length and $\mathrm{C}$ is the sample concentration. By applying LPE to Eqn. 14 and considering the error in L to be zero:

$$
u^{2}\left(A_{\text {conc }}\right)=(L C)^{2} u^{2}()+(L)^{2} u^{2}(C)
$$

Molar absorption coefficient is obtained as the mean value of five measured absorbances divided by the sample concentration and path-length $(1 \mathrm{~cm})$ at each $\mathrm{pH}$. The standard uncertainty of molar absorption is evaluated as the standard deviation of these measurements. The uncertainty of sample concentration was evaluated before. The standard uncertainty of absorbance measurement was obtained by combination of these three contributions by using the expression:

$u^{2}(A)=u^{2}\left(A_{c a l}\right)+u^{2}\left(A_{r e p}\right)+u^{2}\left(A_{\text {conc }}\right)$

The uncertainty budget for the measured absorbance at $\mathrm{pH} 9.54$ is shown in table 5 . In this case, the higher contributions are due to the repeatability in absorbance measurements, the calibration of spectrophotometer and the concentration of the work standard. 
A Practical Example on Uncertainty Evaluation: Spectrophotometric Determination of pK

Table 5. Uncertainty budget for the measured absorbance at $\mathrm{pH} 9.54$

\begin{tabular}{|c|c|c|c|c|}
\hline Quantity & Estimate & Standard Uncertainty & $\begin{array}{c}\text { Sensitivity } \\
\text { coefficient }\end{array}$ & $\begin{array}{c}\text { Uncertainty } \\
\text { contribution }\end{array}$ \\
\hline $\mathrm{A}_{\text {rep }}$ & 0.434 & $6.5 \times 10^{-3}$ & 1 & $6.5 \times 10^{-3}$ \\
\hline $\mathrm{A}_{\text {cal }}$ & 0 & $5 \times 10^{-3}$ & 1 & $5 \times 10^{-3}$ \\
\hline $\mathrm{A}_{\text {conc }}$ & 0 & $4.69 \times 10^{-3}$ & & $2.95 \times 10^{-3}$ \\
\hline $\mathrm{E}$ & 8700 & 59 & $8 \times 10^{-5}$ & $3.6 \times 10^{-3}$ \\
\hline $\mathrm{C}$ & $5 \times 10^{-5}$ & $4.18 \times 10^{-7}$ & 8700 & \\
\hline $\mathrm{A}$ & 0.434 & $9.45 \times 10^{-3}$ & & \\
\hline
\end{tabular}

Finally, the uncertainty of the logarithmic term $\left(\log \left(\mathrm{A}_{\mathrm{I}} /\left(\mathrm{A}_{\mathrm{II}}-\mathrm{A}_{\mathrm{I}}\right)\right)\right)$ in Eqn. 1 is also evaluated according to LPE as:

$$
u\left[\log \left(\frac{A_{I}}{A_{I I} A_{I}}\right)\right]=\sqrt{\left(\frac{A_{I I}}{A_{I}\left(A_{I I} A_{I}\right) \ln 10}\right)^{2} u^{2}\left(A_{I}\right)+\left(\frac{1}{\left(A_{I I} A_{I}\right) \ln 10}\right)^{2} u^{2}\left(A_{I I}\right)}
$$

Table6. Uncertainty budget for logarithmic term $\log \left(A_{I I} /\left(A_{I I}-A_{I}\right)\right)$ at $\mathrm{pH} 9.54$

\begin{tabular}{|c|c|c|c|c|}
\hline Quantity & Estimate & Standard Uncertainty & Sensitivity coefficient & $\begin{array}{c}\text { Uncertainty } \\
\text { contribution }\end{array}$ \\
\hline $\mathrm{A}_{\mathrm{II}}$ & -0.232 & $1.4 \times 10^{-2}$ & 3.37 & $4.75 \times 10^{-2}$ \\
\hline $\mathrm{A}_{\mathrm{I}}$ & -0.103 & $1.27 \times 10^{-2}$ & 7.58 & $9.64 \times 10^{-2}$ \\
\hline $\log \left(\mathrm{A}_{\mathrm{I}} /\left(\mathrm{A}_{\mathrm{II}} \mathrm{A}_{\mathrm{I}}\right)\right)$ & $-9.78 \times 10^{-2}$ & $1.07 \times 10^{-1}$ & & \\
\hline
\end{tabular}

The uncertainty budget for the measurement at $\mathrm{pH} 9.5$ is shown in Table 6 . The main uncertainty contribution is due to the parameter $A_{I}$.

\subsection{Determination of $\mathrm{pK}_{\mathrm{a}}$}

Table 7. Measured absorbances at different experimental $p H$ values and their logarithmic transformations according to Hildebrand and Reilley method, with their corresponding uncertainties

\begin{tabular}{|l|l|l|l|l|l|}
\hline $\mathrm{pH}$ & $\mathrm{u}(\mathrm{pH})$ & $\mathrm{A}(258 \mathrm{~nm})$ & $\mathrm{u}(\mathrm{A})$ & $\log \left(\mathrm{A}_{\mathrm{I}} /\left(\mathrm{A}_{\mathrm{II}}-\mathrm{A}_{\mathrm{I}}\right)\right)$ & $\mathrm{u}\left(\log \left(\mathrm{A}_{\mathrm{I}} /\left(\mathrm{A}_{\mathrm{II}}-\mathrm{A}_{\mathrm{I}}\right)\right)\right)$ \\
\hline 6.12 & 0.034 & 0.332 & 0.009 & & \\
\hline 6.50 & 0.032 & 0.332 & 0.008 & & 5.642 \\
\hline 6.79 & 0.031 & 0.333 & 0.010 & -2.364 & 5.401 \\
\hline 7.10 & 0.031 & 0.333 & 0.009 & -2.364 & --- \\
\hline 7.50 & 0.032 & 0.332 & 0.010 & --- & 1.892 \\
\hline 7.83 & 0.034 & 0.335 & 0.010 & -1.883 & 0.406 \\
\hline 8.23 & 0.037 & 0.346 & 0.009 & -1.192 & 0.256 \\
\hline 8.57 & 0.041 & 0.356 & 0.009 & -0.938 & 0.135 \\
\hline 9.06 & 0.056 & 0.391 & 0.010 & -0.467 & 0.113 \\
\hline 9.29 & 0.059 & 0.409 & 0.009 & -0.304 & 0.107 \\
\hline 9.54 & 0.062 & 0.435 & 0.009 & -0.098 & 0.113 \\
\hline 9.78 & 0.065 & 0.466 & 0.009 & 0.136 & 0.179 \\
\hline 10.00 & 0.068 & 0.512 & 0.009 & 0.539 & 0.326 \\
\hline 10.24 & 0.071 & 0.537 & 0.010 & 0.880 & 0.954 \\
\hline 10.69 & 0.077 & 0.555 & 0.010 & 1.394 & 2.208 \\
\hline 11.00 & 0.082 & 0.560 & 0.012 & 1.756 & 8.569 \\
\hline 11.51 & 0.098 & 0.563 & 0.011 & 2.364 & \\
\hline 11.99 & 0.105 & 0.564 & 0.010 & & \\
\hline 12.26 & 0.108 & 0.564 & 0.011 & & \\
\hline 12.56 & 0.113 & 0.545 & 0.009 & & \\
\hline
\end{tabular}

The measured absorbances at the experimental $\mathrm{pH}$ values, as well as the logarithmic transformation according to Hildebrand and Reilley method, with their corresponding uncertainty values are shown in Table 7. In order to calculate the $\mathrm{pK}_{\mathrm{a}}$, weighted least squares regression was applied using the points from $\mathrm{pH} 7.81$ to 11.00 . The equation of the obtained curve was $\mathrm{Y}=(0.91 \pm 0.05) \mathrm{X}+(9.49 \pm$ 0.04). The final result for the estimated $\mathrm{pKa}$ of acetaminophen, with a $95 \%$ of confidence level, was $9.49 \pm 0.08$, what lies in concordance with the theoretical one (9.50). Finally by applying ordinary least squares the curve equation was $\mathrm{Y}=(0.90 \pm 0.03) \mathrm{X}+(9.49 \pm 0.03)$, leading to a $\mathrm{pK}_{\mathrm{a}}$ value 9.49 \pm 0.06 . 


\section{CONCLuSions}

A step-by-step practical example, focused on the evaluation of uncertainty in experimental measurements, has been proposed. Different topics were considered:

- The evaluation of the uncertainty in standard concentration according to GUM.

- The evaluation of the uncertainty in absorbance measurements, including the contribution of repeatability, calibration data and work standard concentration.

- The evaluation of the uncertainty in $\mathrm{pH}$ measurements according to IUPAC recommendations.

- The uncertainty propagation after applying Hildebrand - Reilley method to calculate the $\mathrm{pK}_{\mathrm{a}}$ value.

- The use of weighted least squares when errors in both variables are present.

For these reasons, this tutorial can be considered as a good training example for people working in uncertainty evaluation and propagation.

The main sources of uncertainty in the measured absorbance were the repeatability of absorbance measurements, the calibration data of spectrophotometer and the purity and weighted mass of acetaminophen. In the measurement of $\mathrm{pH}$, the higher contributions are due to the potential measurements.

\section{REFERENCES}

[1] EURACHEM/CITAC, Quantifying Uncertainty in Analytical Measurements, $2^{\text {nd }}$ Ed., http://measureme ntuncertainty.org/mu/guide/index.html (2002).

[2] Hildebrand G. P. and Reilley C. N., New indicator for complexometric titration of calcium in presence of magnesium, Anal. Chem. 29 (2), 258-264 (1957).

[3] Guide to the Expression of Uncertainty in Measurement, ISO, Genève, Switzerland (1993). Corrected and reprinted in 1995.

[4] Asuero A. G., Gonzalez G., de Pablos F. and Gomez-Ariza J. L., Determination of the optimum working range in spectrophotometric procedures, Talanta 35(7), 531-537 (1988).

[5] Danzer K. and Currie L. A., Guideline for calibration in analytical chemistry - Part 1. Fundamentals and single component calibration, Pure Appl. Chem. 70 (4), 993-1014 (1998).

[6] Miller J. N. and Miller J. C., Statistic and Chemometrics for Analytical Chemistry, $6^{\text {th }}$ Ed., Pearson education Ltd.: U.K (2010).

[7] Gonzalez A. G., Herrador M. A., Asuero A. G. and Sayago A., The correlation coefficient attacks again, Accred. Qual. Ass. 11 (5), 256-258 (2006).

[8] Ripley B. D. and Thompson M., Regression techniques for the detection of analytical bias, Analyst 112 (4), 337-383 (1987).

[9] González A. G. and Asuero A. G., Computational program for validating analytical methods, Fresenius J. Anal. Chem. 346 (10-11), 885-887 (1993).

[10] Riu J. and Rius F. X., Assessing the accuracy of analytical methods using linear regression with errors in both axes, Anal. Chem. 68 (11), 1851-1857 (1996).

[11] González A. G. and Asuero A. G., Computational method for unbiased evaluation of equivalence volumes and ionization constants from potentiometric acid-base titrations, Anal. Chim. Acta 257 (1), 29-33 (1992).

[12] Herrador M. A. and González A. G., Evaluation of measurement uncertainty in analytical assays by means of Monte-Carlo simulation, Talanta 64 (2), 415-422 (2004).

[13] Jurado J. M. and Alcázar A., A software package comparison for uncertainty measurement estimation according to GUM, Accred. Qual. Assur. 10 (7), 373-381 (2005).

[14] Buck R. P., Rondinini S., Covington A.K., Baucke F. G. K., Brett C. M. A., Camoes M. F., Milton M. J. T., Mussini T., Naumann R., Pratt W. W., Spitzer P. and Wilson G. S., Measurement of pH. Definition, standards, and procedures (IUPAC Recommendations 2002), Pure Appl. Chem. 74 (11), 2169-2200 (2003). 
[15] Ramachandran R. and Rashmi, Uncertainty of measurement in spectrophotometric analysis: A case study, Analyst 124 (7), 1099-1103 (1999).

[16] Silva G. M. S., Uncertainty of analytical determinations, J. AOAC Int. 86(5), 1077-1083 (2003).

Citation: E. Montaña et al., "A Practical Example on Uncertainty Evaluation: Spectrophotometric Determination of $p K_{a}$ ", International Journal of Advanced Research in Chemical Science (IJARCS), vol. 5, no. 1, pp. 20-28, 2018. http://dx.doi.org/10.20431/2349-0403.0501004

Copyright: (C) 2018 Authors. This is an open-access article distributed under the terms of the Creative Commons Attribution License, which permits unrestricted use, distribution, and reproduction in any medium, provided the original author and source are credited. 